\title{
Quantitative Analysis of the Fishing Activity in the Gulf of Manfredonia (Gargano, South-Italy)
}

\author{
Luca Grilli ${ }^{1}$, Pasquale Marcello Falcone ${ }^{2}$
} ${ }^{1}$ Dipartimento di Scienze Economiche, Matematiche e Statistiche Università degli Studi di Foggia, Foggia, Italy; ${ }^{2}$ Post-Graduate at
Faculty of Economics, Università degli Studi di Foggia, Foggia, Italy.
Email: 1.grilli@unifg.it

Received March $18^{\text {th }}, 2010$; revised April $1^{\text {st }}, 2010$; accepted April $18^{\text {th }}, 2010$.

\begin{abstract}
The Manfredonia City Marine is the third in Italy both for its size and for its nation-wide importance, in the last decade a considerable crisis has been registered in this economic sector as shown by the always decreasing number of fishing boats registered in the Harbour-Office. As a result of such a reduction in the number of fishing boats, a remarkable fall-off in the production occurs. The fishing activity registers a deep legislative, organizational and operational transformation. The European Community, in order to face the indiscriminate impoverishment of the ichthyic inheritance, has provided incentives for the fishing boats' casting off, by mean of an adequate reward. This paper aims to quantitatively analyze the fishing activity in the Gulf of Manfredonia in order to present a significant picture of the forthcoming situation on the basis of real data. To this end, we adopt a Prey-Predator model in discrete time that is suitable to describe properly the dynamics of an ecosystem in which just two species interact: predator and prey. The results show worrying forecasts. The fishing boats' number presents a decreasing dynamic and, above all, we record a remarkable reduction in the stock of fishes in the Gulf of Manfredonia. The quantity of fishes, in twenty years, will be reduced of $28 \%$. The Gulf sea, once rich in codfishes, mullets, cuttlefishes, octopus etc., runs the risk (on the basis of the results obtained in this paper) of making such species rare. The situation should be much more critical if the fishing activity in the Gulf runs at the rhythms of one decade ago. We apply the model at data from 1995, and we obtain catastrophical results; the number of fishing boats in the sector in 2015 should be 107 units (77\% less) and the ichthyic inheritance about 16345 tons $(45 \%$ less).
\end{abstract}

Keywords: Renewable Resources, Dynamical Systems, Sustainable Development

\section{Introduction}

Manfredonia (Gargano, South-Italy), a fishing and sailing city, possesses one of the most representative marine of Italian coasts (third in Italy).

In the last decade the situation of marine activity has been changing and still now it is in the middle of a crisis. In the year 1995, the number of fishing boats registered in the Manfredonia Harbour-Office was 450, and in 2007 we count only 195 boats, and, on average, the fishing boats are about 26 years old (data from Manfredonia Harbour-Office).

The last explicative data show a strong dropping trend of this important economic sector. In the year 1995, the registered production was 7072 tons corresponding to a value of 17071134 Euro; in the year 2007 we register a production of 1014 tons equivalent to 5393154 Euro.

The reasons for such a situation, that is undoubtedly hard and worrying, are quite complex. It should be simplistic to blame the high cost of oil weighing upon the management costs of a fishing boat (from 40 up to 60 percent according to the boat). The high cost of oil has only increased the speed of a problem which was latent and was under-estimated; this problem leads directly to a dangerous crisis which is representative of a very bad situation. A proof for it is given by the recent strikes and positions adopted by the professional fishing category in order to reveal the increasing state of difficulty of the fishing activity. It is worth considering also that the fishing activity is undergoing a deep transformation from the legislative, managerial and operational viewpoint.

The European Community, which is the Member States, has impressed a vigorous legislative veer in order to face the indiscriminate impoverishment of the ichthyic inheritance, which was subjected to an uncontrolled and irrational harvesting activity. The European 
Community, followed by the Italian Government, has recently provided incentives, by mean of an adequate reward, for the fishing boats' casting off. As a consequence, many fishers-ship-owners, close to the pension, has taken this opportunity that was, for many reasons, a providential help. This incentive has been suspended by the Minister of Agriculture in august 2005. It is realistic to suppose that the normative for the fishing boats' casting off will be reactivated with rewards more attractive compared with the past. For the moment the incentives have not been restored, although it is worth noting that the "Fondo Europeo sulla Pesca" (F.S.P.) has been brought into force for the period 2007-2013. The F.S.P. will provide funds to fishers and ship-owners in the case of a temporary stop of the fishing activity due to public safety or natural emergency but also for professional training and early-retirement.

The problem of resource extraction activity is of great interest and it is studied by mean of many different approaches. In Grilli [1,2], the author studies a differential game in which players are overlapping generations of extractors of a renewable good, the author considers the case in which players are not perfectly symmetric.

In this paper we apply a discrete time model in order to analyze and understand the evolutionary dynamic of the ecosystem. We focus our attention on the problem of the ichthyic inheritance's impoverishment in the Adriatic Sea and in particular in the Gulf of Manfredonia. In order to have a picture of the future situation that is based on real data we adopt a prey-predator model in discrete time. Such mathematical model is able to describe the dynamic of an ecosystem in which only two species interact: the predator (in the case in point we consider the fishing boats active in the Gulf of Manfredonia) and the prey (the ichthyic inheritance in the zone).

\section{The Model}

In order to construct the model it is necessary to know, a priori, the number of preys (fishes) and predators (fishing boats). The number of fishing boats registered in the Manfredonia Harbour-Office for the year 2007 (the most recent official data available for catch and fishing boats) is 195 units. The computation of the number of fishes, exactly the catch measured in tons, it is not trivial at all. In this paper, in order to estimate the number of fishes in the Gulf of Manfredonia, we consider the mean harvesting rate in the Adriatic Sea, which is about $2 \%$. The last information together with the average quantity of catch in the last years (we consider the last five years in the period 2003-2007), allows us to estimate the stock of fishes in the zone. In fact, the ichthyic stock is computed

${ }^{1}$ European Fishery Fund using the ratio between the average catch and the average harvesting rate:

The data about the catch in the zone referred to the period considered are:

- Year $2003=1014$ tons;

- Year $2004=1530$ tons;

- Year $2005=1990$ tons;

- Year $2006=2370$ tons;

- Year $2007=1895$ tons;

So the average catch results equal to 1760 tons.

The ichthyic stock is:

$$
\text { IchtyicStock }=\frac{\text { Catch }}{\text { Harvesting_Rate }}
$$

that is:

$$
\text { IchtyicStock }=\frac{1760}{0,02}=87983 \text { tons }
$$

It is necessary to underline that this data refers to the entire Adriatic Sea. Knowing that the marine of Manfredonia, for its position and size, is not able to reach the entire area we have established, comparing the production of Manfredonia to the production of other competing cities in the Adriatic Sea (Ancona, San Benedetto del Tronto), that the Marine of Manfredonia can influence only one third of the ichthyic stock in the zone. As a consequence the data interesting for our analysis is 29327 tons.

In the model, let us consider that at time $t=0$ the ichthyic inheritance of the Gulf is 29327 tons, and the number of fishing boats is 195 units. Let us suppose that, if it is known the quantity of predators and preys at time $t$, at time $t+1$ the evolutionary dynamics is the following:

$$
\left\{\begin{array}{l}
\text { Pr edators } \\
\text { Pr eys } \\
t_{t+1}=-0,39 \text { Pr } \text { edators }_{t}+1,022 \operatorname{Pr} \text { eys }_{t}
\end{array}\right.
$$

In order to understand the coefficients' choice it is necessary to present criteria adopted for their computation.

The coefficient $a_{1,1}(0,2)$ must undoubtedly be $<1$ since it represents the way in which the predators evolve in absence of preys, at time $t+1$ the absence of fishes pushes the fishers out from the market even if a little part of them decides to continue the activity in the short run.

The coefficient $a_{1,2}(0,002)$ represents the variation rate of fishing boats as a function of the ichthyic stock.

The coefficient $a_{2,1}(-0,39)$ indicates the harvesting ability, more precisely, how the number of fishes is affected by the harvesting activity.

The coefficient $a_{2,2}(1,022)$ describes how fishes evolve in absence of predators. In the model, for sake of simplicity, we suppose that the only cause of death for fishes derives from predators. This coefficient is computed as follows:

Ichthyic Stock 2007 + Catch 2007

Ichthyic Stock 2007 
Once the evolutionary dynamic is established it is possible, by mean of simple elements of linear algebra (matrix diagonalization), to provide a picture of the fishing activity in Manfredonia for the future in the next years. The model, of course, provides answers that are more accurate if we look at the short term. We are interested in the evolution of predators (fishing boats) and preys (fishes) in 20 years.

Let $A$ the coefficient matrix derived by the evolutionary dynamic described above, if we suppose that such dynamic does not change, it is clear that the solution of our problem is:

$$
\left(\begin{array}{l}
\operatorname{Pr} \text { edators }_{20} \\
\operatorname{Pr} e y s_{20}
\end{array}\right)=A^{20}\left(\begin{array}{l}
\operatorname{Pr} \text { edators }_{0} \\
\operatorname{Pr} e^{2} s_{0}
\end{array}\right)
$$

If the matrix $A$ is diagonalizable, let $S$ be the matrix of eigentvectors associated to the eigenvalues of $A$ and let $D$ be the diagonal matrix of its eigenvalues, it holds:

$$
A^{20}=S^{-1} D^{20} S \text {. }
$$

The matrix $A$ is diagonalizable in the field of real numbers since it presents two eigenvalues $\lambda_{1}$ and $\lambda_{2}$, that are real and distinct numbers:

$$
\lambda_{1} \approx 1,02 \text { and } \lambda_{2} \approx 0,22 \text {. }
$$

The space of eigenvector associated to the eigenvalue $\lambda_{1}$ is $(\forall t \in \mathfrak{R} \backslash\{0\})$ :

$$
x_{1} \approx\left(\begin{array}{l}
t \\
410,952 \cdot t
\end{array}\right)
$$

The space of eigenvector associated to the eigenvalue $\lambda_{2}$ is $(\forall t \in \mathfrak{R} \backslash\{0\})$ :

$$
x_{2} \approx\left(\begin{array}{l}
t \\
0,04748 \cdot t
\end{array}\right)
$$

The matrix $S$ which diagonalizes $A$ is obtained using the previous eigenvectors as its columns.

The last information we need in order to apply the model is the following:

$$
\left(\begin{array}{l}
\text { Predators } \\
\text { Preys }
\end{array}\right)=\left(\begin{array}{l}
195 \\
29327
\end{array}\right)
$$

We have all the information we need in order to complete our analysis.

\section{Results}

The solution of the model, as indicated in the previous section, is the following:

$$
\begin{aligned}
& \left(\begin{array}{l}
\operatorname{Pr} \text { edators }_{20} \\
\operatorname{Pr} \text { eys }_{20}
\end{array}\right)=A^{20}\left(\begin{array}{l}
\operatorname{Pr} \text { edators } \\
\text { Pr eys }
\end{array}\right)= \\
& =S^{-1} D^{20} S\left(\begin{array}{c}
\text { Predators } \\
\text { Preys } \\
\text { Pr }
\end{array}\right)
\end{aligned}
$$

The last equation leads to the following result:

$$
\left(\begin{array}{l}
\text { Pr edators } \\
\text { Preys }
\end{array}\right)=\left(\begin{array}{l}
110 \\
18453,23
\end{array}\right)
$$

This analysis shows a very critical situation. Not only for the number of fishing-boats, which is in a worthy decrease, but above all for the important ichthyic inheritance's impoverishment in the area of Manfredonia.

Data show an alarming situation, in 2038 the stock of fishes will decrease of $28 \%$ (from 29327 tons up to only 18453,23 ), as a consequence about 85 fishing-boats will exit the market and as a result 435 workers (considering an average of 5 workers per ship) will be dismissed. Some years ago the Gulf was rich in codfishes, mullets, cuttlefishes, octopus etc, and all such species risk to become rare.

It is worth noting that the situation could be even worst if the present fishing activity should follow the extraction rate of one decade ago. If we apply this model to data of the year 1995, when the fishing boats registered in the Manfredonia Harbour-Office were 450 with more than 2000 workers and a catch of about 7702,5 tons, we should comment a dramatic situation: the number of fishing boats in the year 2015 should be 107 units only $(-77 \%)$ and the ichthyic stock should be only 16345 ton $(-45 \%)$.

Often data and numbers are more eloquent than many words, such numbers show a dramatic situation. Dealing with the problem of resource extraction of a natural resource it is necessary to consider the problem of intergenerational equity. In fact actions of present generations (in terms of extraction rates) influence the choices of future generation in an obvious way. It is well known among economists that if extractors do not care about the effects of their extraction policies on future levels of stock of resource this can result in the so called "tragedy of commons" [3-5]. It is necessary to define in more details the concept of "intergenerational equity". Rawls [6] claims: "...consider the question of justice between generations. There is no need to stress the difficulties that this problem raises. It subjects any ethical theory to severe if not impossible lest",

Solow [7] considers the problem of a natural resource: "the current generation is always entitled to take as much resource out of the common intertemporal pool as it can, provided only that it leaves behind the possibility to each succeeding generation can be as well off as this one"

It seems that, in an environmental context, with "intergenerational equity" we can mean that the extraction strategies of present generations can satisfy their own needs and in the same time guarantee to future generations to do the same. This paper wants to be a contribution in such direction. 


\section{REFERENCES}

[1] L. Grilli, "Resource Extraction Activity: An Intergenerational Approach," Game Theory and Applications, Vol. 13, 2008, pp. 45-55.

[2] L. Grilli, "A Stackelberg Differential Game with Overlapping Generations for the Management of a Renewable Resource," Statistical Science and Interdisciplinary Research, Vol. 6, Modeling, Computation and Optimization, 2009, pp. 221-235.

[3] H. S. Gordon, "The Economic Theory of a Common Property Resource," Journal of Political Economy, Vol. 62, No. 2, 1954, pp. 124-142.

[4] H. Hotelling, "The Economics of Exhaustible Resource," Journal of Political Economy, Vol. 39, No. 2, 1931, pp. 137-175.

[5] A. C. Pigou, "The Economics of Welfare," Macmillan, London, 1932.

[6] J. Rawls, “A Theory of Justice," Harvard University Press, Cambridge, 1971.

[7] R. M. Solow, "On the Intergenerational Allocation of Natural Resource," Scandinavian Journal of Economics, Vol. 88, No. 1, 1986, pp. 141-149.

[8] P. Burton, "Intertemporal Preferences and Intergenerational Equity Considerations in Optimal Resource Har- vesting," Journal of Environmental Economics and Management, Vol. 24, No. 2, 1993, pp. 119-132.

[9] C. Chiarella, M. C. Kemp, N. V. Long and K. Okuguchi, "On the Economics of International Fisheries," International Economic Review, Vol. 25, No. 1, 1984, pp. 85-92.

[10] C. W. Clark, "Mathematical Bioeconomics: The Optimal Management of Renewable Resources," Wiley, New York, 1976.

[11] S. Clemhout and H. Wan, Jr., "Dynamic Common Property Resources and Environmental Problems," Journal of Optimization Theory and Applications, Vol. 46, No. 4, 1985, pp. 471-481.

[12] R. Fischer and L. Mirman, "Strategic Dynamic Interactions: Fish Wars," Journal of Economic Dynamics and Control, Vol. 16, No. 2, 1992, pp. 267-287.

[13] C. Plourde and D. W. K. Yeung, "Harvesting of a Transboundary Replenishable Fish Stock: A Noncooperative Game Solution," Marine Resource Economics, Vol. 6, 1989, pp. 57-71.

[14] J. G. Riley, "The Just Rate of Depletion of a Natural Resource," Journal of Environmental Economics and Management, Vol. 7, No. 4, 1980, pp. 291-307.

[15] R. M. Solow, "Intergenerational Equity and Exhaustible Resources," Review of Economic Studies Symposium, 1974, pp. 29-46. 